\title{
Paragangioma (Clomustumor), Phäochromocytoma (в региона на главата и шията)
}

\author{
Е. Ценев \\ Klinicum PAN Köln-Deutschland, HNO Abteilung \\ Leiter: Dr. med habil. E. Zenev
}

\section{Резюме:}

В последните години имахме възможност да наблюдаваме и оперираме няколко пациенти с параганглиоми (гломусни) тумори на бифуркацията и такива, локализирани в средното ухо. Параганглиомите са сравнително редки, силно васкуларизирани тумори и с предпочитание възникват в зоната на гломус каротикус.

\footnotetext{
Abstract

Paragangliomas and paraganglioma (syndrom ) are rare tumors of neutral crest (neuroendocrinae) origin. They are benign in the majority of cases and are characterized by strong vascularisation. In the head and neck region they most commonly occur as carotid body tumors. Jugulotympanic and especially vagal paragangliomas are seen less frequently.
}

$\Pi$ араганглионерните тумори се предполага, че възникват ,genius loci“ от гломусните телца, които хистологично представляват високоорганизирани артериовенуларни анастомози, формирайки тънки нодуларни фокуси в зоната на ухото, пръстите на краката, ръцете, бифуркацията на а. carotis communis, коремната и торакалната кухина и др. Аферентните артериоли се ограждат от съединително-тъканна капсула, която създава тънки еластични капсула повлекла, които се спускат към паренхима на тумора като септи, които ограждат отделни анастомизиращи капилярни фокуси, богато инервирани със симпатикови и миелинизирани нервни клончета. Тук гломерулите функционират като shunt или bypass регулиращ механизъм върху преминаващия поток на кръвта, респ. оказват контрол посредством регистриране на кръвното налягане, температурата и други данни на циркулаторната система. Glomus caroticum функционира като своеобразен датчик-хеморецептор за регистрация на евентуална хипоксия, хиперкапния ниво на $\mathrm{pO}_{2}$ и $\mathrm{CO}_{2}$ или ацидоза $\mathrm{pH}$ на крьвта, а също и на регулацията на дишането, сърдечната честота и кръвното налягане. Връзката между Glomus caroticum и централните представителства се осъществява чрез n. glossopharyngeus.

Параганглиомите са предимно доброкачествени тумори, изхождащи от параганглиите на вегетативната нервна система. Те принадлежат към групата на невроендокринните неоплазми, които като правило са изключително богато васкуларизирани. Последното е най-често пречка за радикалното им хирургическо екстирпиране. В региона на главата 
и шията те се маркират най-често като Glomus caroticum, докато другите локализирани в зоната на bulbus v. jugularis се нотифицират като paraganglioma jugulotympanale s. jugulovagale. Радикалното хирургическо отстраняване на локално обемни инфилтриращи тумори често завършва с постоперативни тежки инвалидизирания от увреждане на съседно разположени черепномозъчни нерви и магистрални съдове.

При около $30 \%$ до $45 \%$ от параганглиомите се демонстрират с различни по тежест клинични симптоми. Доказано е, че клиничните синдроми се обуславят до известна степен от мутации на гени SDHD, SDHC и SDHB (недостатъчна активност на D, C и B Succinatgehydogenase). Има емпирични наблюдения, че много по-често се срещат гломусни тумори сред хора, които живеят в бедни на кислород райони, напр. Мехico city, или такива с хронична обструктивна белодробна болест (Ив. Ценев, 1971). Наблюдаваните пациенти с параганглиоми при гени $\mathrm{SDHB}$, съчетани с феохромоцитоми, евентуално и при SDHD са сравнително редки, докато пациенти със SDHC заболяването е протичало и с появата на солитарни доброкачествени параганглиоми на главата и шията. Унаследяването се осьществява и за трите синдрома по автозомно-доминантен път. При пациенти със SDHD съществува висок риск от развитие на параганглиом, ако мутацията се наследява през бащата (,parent-of origin-dependent-inheritance“).

\section{Въведение}

Параганглиомите се представят най-често като доброкачествени новообразувания на параганглиите на вегетативната нервна система на главата и шията. Тези силно васкуларизирани пространствено заемащи тумори принадлежат към групата на невроендокринните образувания. Параганглиите се числят към многобройните ендокринни жлези на периферната вегетативна система с невроектодермален произход, които се намират в човешкото тяло от основата на черепа до тазовите органи. Феохромоцитомите изхождат също от параганглиите и хистологично не могат да се разграничат от параганглиомите (Baysal, B. E. - 2002).

\section{Терминологични определения}

Понятието „Paraganglioma“ и „Рhäochromocytoma“" в клиничното ежедневие се използва без единно мнение кое наименование е правилно. Според препорьките на Neumann, HPH et all. (2004) феохромоцитомите се намират в интраторакалната и абдоминалната кухини, докато параганглиомите се локализират в главата и шията. Докато феохромоцитомите имат значителна продукция на катехоламини с консекутивни клинични симптоми (рязко повишаване на кръвното налягане; тахикардия, неспокойствие-адреналинов ефект, то секреторно активните параганглиоми са изключително редки. Параганглиомът най-често в литературата се нарича Glomus tumor seu Chemodectoma. Гломусният тумор често може да се сгреши с доброкачествени тумори на кожата в субкутанната съединителна тъкан, където се приемат като разраствания на миоепителиалните клетки около артерио-венозните сплетения (D'Acri A. M. et all - 2002). Параганглиомите много често са титуловани хемодектоми и не е коректно да се наричат по същия начин и туморите в областта на главата и шията, поради което се предпочитат названията Glomus tumor seu Paraganglioma. He е подходящо названието Chemodektoma, независимо че туморният паренхим се генерира от хеморецепторите и най-важното този тип има характерна склонност да се оцветява с хромови соли при хистологичната типизация.

\section{Разпространение и локализация}

Параганглиомите са много редки тумори и по преценка на клиниката са около 0,2-0,3\% спрямо общия брой лекувани болни, поради което те се акцептират като казуистика не само от нас, но и от други автори (Lee, J. H. et all. - 2002). Параганглиомите най-често възникват от артериовенозните струпвания в областта на Glomus caroticum (GC), следвани от Glomus jugulare (GJ), от зоната на bulbus v. jugularis, Glomus vagale (GV), параганглиоми в цервикалния сектор на n. vagus (Biller, H. F. et all. 1989), тумори в зоната на Plexus tympanicus - Glomus tympanicus (GT) или такива, локализирани в носната кухина, паротиса, ларинкса, щитовидната жлеза и др.

Функция на параганглиомите в областта на главата и шията. Каротидният възел се локализира по задната стена на бифуркацията на a. carotis communis. Има приблизително големина 5 х 3 $\mathrm{x}$ 1,5 мм и е с червено кафяв цвят. Описан е за първи път през 1743 г. от Haller, докато параганглиомът в областта на bulbus v. jugularis е открит 
и описан от Valentin през 1840 г. По късно се описва гломусно струпване в региона на n. vagus от White (цитат по Sobol, S. M. et all. - 1990) - glomus vagale.

\section{Етиология}

Произходът на параганглиомите до настоящия момент все още не е напълно изяснен, но има наблюдения, че високият процент на GC се наблюдава сред популации, обитаващи региони над 2000 метра надморско ниво и пациенти с обструктивна белодробна болест, което дава основание да се приеме концепцията, че причината е хроничната хипоксия.

\section{Възрастово и полово разделение}

Параганглиомите се намират във всяка възраст, но доминират между 30 и 60-годишните, с предпочитание според различните статистики към жените в съотношение 3:1-4:1. (Kinermann, R. W. et all. - 2001, Schick, B. et all. - 1998)

\section{Симптоматика}

Клиничната картина на GC е твърде разнообразна, но началните етапи на развитие остават напълно инапарентно от ежедневните прояви на пространствено заемащ процес в латералната страна на шията. Особено при бързо нарастващи туморни формации е възможно появата на различна степен на дисфагия, чувството на globus pharyngis, както и функционални смущения в моториката на $\mathrm{n}$. facialis, $\mathrm{n}$. glossopharyngeus, $\mathrm{n}$. vagus, n. accessorius, n. hypopharyngis, появата на синдрома на Horner, рецидивиращи синкопи при натиск в областта на sinus caroticus са прояви на туморна инфилтрация в зоната на шийния симпатикус (Boedeker, C. C. et all. - 2005). Найчесто при палпиране в латералната страна на шията се опипва безболезнена туморна маса с добра подвижност в хоризонталната плоскост на шията в сравнение с вертикалната, симптом, познат като „Fontaine Scar s. Zeichen“. Туморите на средното ухо се маркират почти от началото на развитието си с шум, синхронен с пулса, последван от прогресивно проводно намаление на слуха, докато при югуларните хемодектоми като правило настьпват парези и парализи на последната група (IX, X, XI, XII) черепномозъчни нерви (Gstoettner,W.et all. - 1999). При обективното отоскопично изследване на тимпаналните хемодектоми импонира находката, че в хипотимпаналната част на мембраната се вижда синкаво-червено петно с лека протрузия към канала и с умерена пулсация.

Параганглиомите на вагуса се манифестират с ипсилатерална парализа на гласната връзка, придружена от лек задух, особено при физически усилия, и дрезгав глас. Съобразно големината на тумора при палпация в латералната зона на шията (в зависимост от локализацията на тумора) са проявите от чувство на globus pharyngis, парализа на n. hypoglossus, Horner syndrom, както и парализи на другите черепно-мозъчни нерви. Много малка част от хемодектомите (1-3\%) са хормонално активни и продуцират катехоламини, продукцията на които индуцира появата на тахикардия, тремор, високо кръвно налягане (понякога достига до $220 \mathrm{Hg}$, особено при опит за хирургическото им отстраняване).

\section{Визуализираща диагностика}

При подозрение за съществуването на цервикален параганглиом се използва най-напред като правило първоначално В-сканиращ сонограф с цветно кодиране - доплер сонография - Farbkodirung-Dopplersonographi-F (FKDS), респ. Angio-Mode. При сканиране на авансирали в областта на каротиса хемодектоми се очертават контурите на един гладко отграничен, ехохромно или ехоинхромогенен тумор с характерната форма на лале „Tulpenform“ в зоната на бифуркацията, описвана в англо-американската литература като „goblet deformity“ (фиг. 1). Друг

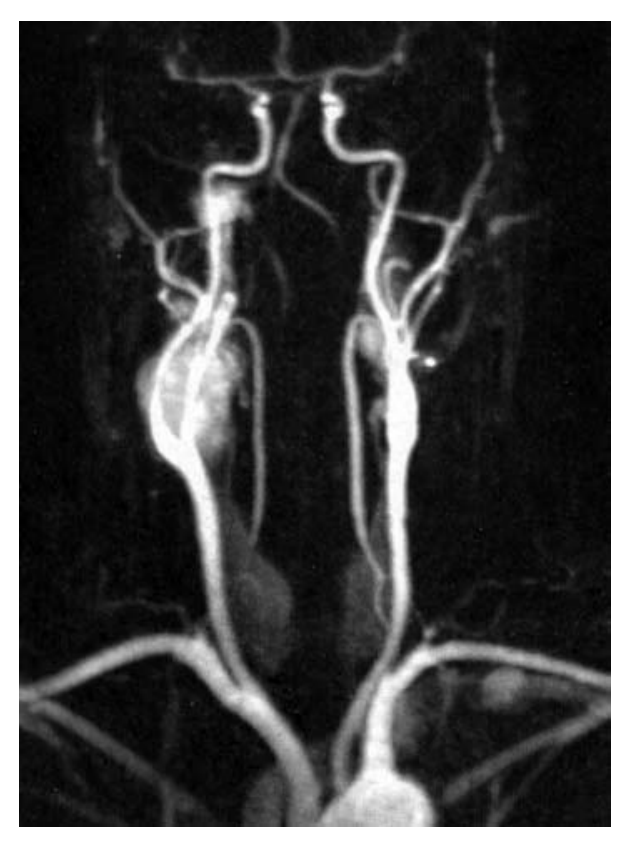

Фиг. 1. Ангио MRT на GC tumor и GJ ляво 
често срещан белег е изместване на a. carotis externa латеро-постериорно спрямо нормалната ѝ позиция, докато при хемодектом на n. vagus $(\mathrm{GV})$, тогава двете - a. carotis interna и a. carotis externa ce намират дислоцирани напред, докато v. jugularis interna е компримирана с изместване дорзално (Thabat, M. Н., Н. Kotob 2001). При комбинираното използване на FKDS много често диагнозата се потвърждава чрез доказване на силно васкуларизирано пространствено, заемащо образувание, съставено от рацемозно разширени артериални и венозни съдове, нерядко показващи и анастомози помежду си. Отрицателна находка при сканирането не означава липса на цервикален параганглиом (Stoeckli, S. J.et all. 2002). За точната преценка мащабното разпространение на цервикалния хемодектом най-добре е използването на ядрено-магнитния томограф (MRI), изследване, което показва ширината и локализацията на туморната формация. Тази визуализираща техника доказва състоянието и съотношението на параганглиома със ствола на a. carotis interna s. communis, a от тук и планиране на евентуално оперативна интервенция и предварителното емболизиране на аферентните съдове или балонна обтурация на артерията. Тук е необходимо да отбележим, че параганглиоми $<1 \mathrm{~cm} \mathrm{D} \mathrm{при} \mathrm{ядрено-магнит-}$ ното сканиране много лесно може да бъдат пропуснати и евентуално маркирани като лимфни възли. Според класификацията на каротидните параганглиоми, предложена от Shamblin et all. (1971) и утвърдена в световната практика, хемодектомите се разделят на:

- при клас I хемодектомът не обгръща (като маншон) артерията,

- при клас II се наблюдава частично обхващане на артерията, докато

- при клас III хемодектомът е обхванал артериалното стебло като пльтен маншон.

При югулотимпаналните параганглиоми MRI e най-показателното визуализиращо изследване, което дава представа за евентуално прорастване на тумора през дурата към ендокраниума, но също така служи и за диференциалнодиагностично детерминиране на параганглиомите от невриномите или туморите на saccus endolymphaticus. При наличие на подозрение за параганглиом е подходящо при извършването на ядрено-магнитното изследване да се проведе и едно и неврорадиологично ангио- графско MRI проследяване и контрастиране за определяне на приводящите туморни съдове. По-нататък е възможно с ангио MRI определяне наличието на синхронни хемодектоми или тяхното изключване. С оглед на възможностите за хирургическо отстраняване на югулотимпаналните параганглиоми през 1988 г. U. Fisch et D. Mattox предложили класификация, която покъсно се препоръчва от UICC, и по която ние работим и сега:

\begin{tabular}{|c|c|}
\hline Стадии & \\
\hline $\mathrm{A}$ & $\begin{array}{l}\text { Туморът е в зоната на plexus } \\
\text { tympanicus на promontorium }\end{array}$ \\
\hline B & $\begin{array}{l}\text { Тумор с инвазия на хипотимпану- } \\
\text { ма, но с интактен костен шпан над } \\
\text { Bulbus venae jugularis }\end{array}$ \\
\hline $\mathrm{C} 1$ & $\begin{array}{l}\text { Тумор с арозия на костния канал на } \\
\text { a. carotis без инфилтрация на съдо- } \\
\text { вата стена }\end{array}$ \\
\hline $\mathrm{C} 2$ & $\begin{array}{l}\text { Тумор с деструкция на вертикалния } \\
\text { костен сегмент на a. carotis }\end{array}$ \\
\hline C3 & $\begin{array}{l}\text { с деструкция на хоризонтал- } \\
\text { стен ход на a. carotis }\end{array}$ \\
\hline $\mathrm{C} 4$ & $\begin{array}{l}\text { с инвазия на foramen lacerum et } \\
\text { avernosus }\end{array}$ \\
\hline $\mathrm{De}_{1 / 2}$ & $\begin{array}{l}\text { Тумор с интракраниална пропагация, } \\
\text { но без инвазия към dura mater. Под- } \\
\text { разделение на подстадии } 1 \text { и } 2 \text { зависи } \\
\text { от ширината на изместване на дурата } \\
\text { медиално. De }{ }_{1}=\text { по-малко от } 2 \mathrm{~cm} \text {, } \\
\mathrm{De}_{2}=\text { по-голямо от } 2 \mathrm{~cm}\end{array}$ \\
\hline $1 / 2 /$ & $\begin{array}{l}\text { Тумори с интракраниална пропага- } \\
\text { ция и интрадурално разпростране- } \\
\text { ние. Подстадии } 1,2 \text { и } 3 \text { според обема } \\
\text { нахлуване към задната черепна ямка } \\
\left(\mathrm{Di}_{1}=\text { по-малко от } 2 \mathrm{~cm} \text {. } \mathrm{Di}_{2}=\text { по- }\right. \\
\text { голям от } 2 \mathrm{~cm} \text {, но по-малък от } 4 \text { см. } \\
\mathrm{Di}_{3} \text { по-голям от } 4 \mathrm{~cm} .\end{array}$ \\
\hline
\end{tabular}

В последните 10 години за диагнозата на хемодектомите все по-често се налага използването на F-Fluorodihydroxyphenylalanin-Positronemissi onstomografie (F-DOPA-PET). Тези изследвания под мое ръководство ние провеждаме регулярно като диагностично средство при болни със съмнителни лезии за хемодектоми и евентуална преценка за проспективната хирургична интервенция (фиг. 2), като последното същевременно се съчетава с т. нар. фузионно изследване ${ }^{18} \mathrm{~F}$ Fluorodopamin-PET ( $\left.{ }^{18} \mathrm{~F}-\mathrm{FDA}-\mathrm{PET}\right),{ }^{18} \mathrm{~F}$-Fluoro2-Deoxy-D-Glucose-PET ( ${ }^{18}$ F-FDG-PET). Тази 


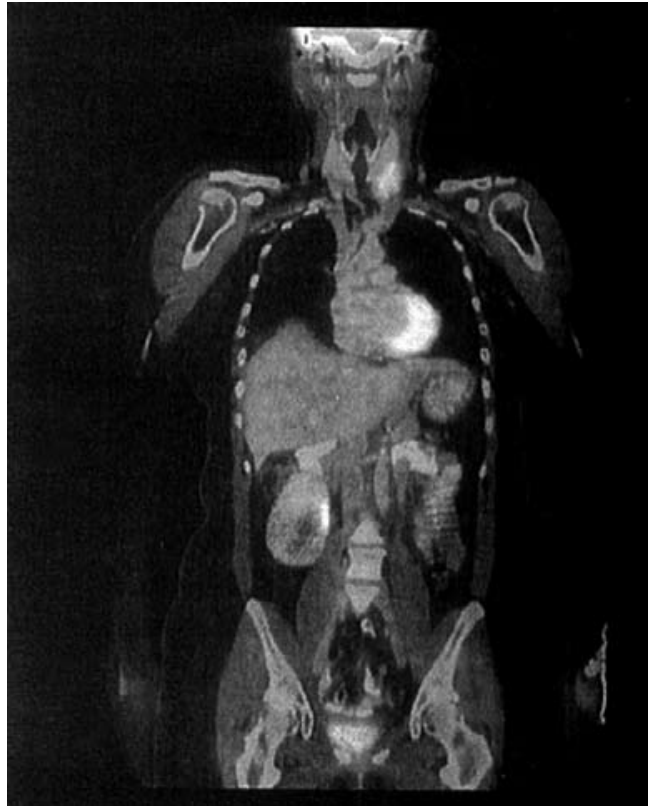

Фиг. 2. РЕТ скенер, натрупване на ${ }^{18}$ F-FDG-PET вляво на шията

комбинация от радиологични и нуклеомедицински изследвания дава възможност за преценка спецификата и сензитивитета на туморната формация (Kayani, L. et all - 2008).

\section{Хистология и имунохистохимия на параганглиомите}

Нормално се приема, че параганглиомите се изграждат от два типа клетки - главни туморни и опорни клетки (Shibahara, J. et all. - 2004), които се подреждат в т. нар. клетьчни клъстери - „Zellballen“, разположени около съдови лумени (фиг. 3), като на много участъци лумените се формират от описаните туморни клетки, които в повече случаи не показват данни за малигнена дегенерация. Според литературните данни малигнените варианти са между 2-10\% (Boedeker, С.

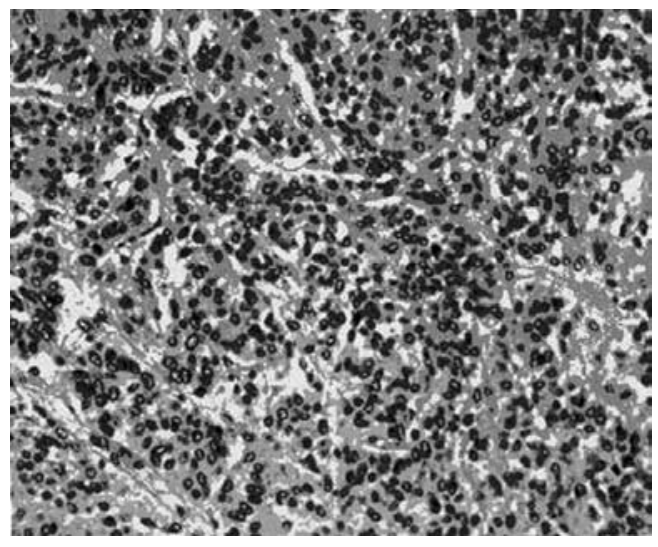

Фиг. 3. Масивно разраснали капиляри с богато струпване на главни туморни клетки
C. et all. - 2004), хистологично твърде трудно детерминирани от нормалните варианти, поради което тук от значение за преценка малигнитета е от значение наличието на метастази във или извън невроендокринните тъкани на тялото. Найчесто далечните метастази са намират в осалните структури, по-рядко са пулмонални, хепатални и др. Окончателната диагноза е възможна само след хистологичната верификация. Микроскопски туморьт импонира с богатството на съдови лумени, които се обгрьщат от туморни клетки, притежаващи тъмни ядра и бедна цитоплазма, а целият тумор е ограден от тънка съединителна капсула. Съответно на невроендокринния характер на тумора имуннохистохимично се намират позитивни реакции и невроендокринни маркери - Synaptophysin, Chromogranin (фиг. 4), Neuronenspezifische enolase (Au W. E. et all. - 1998, Kumaki, N. et all. - 2002). Тези хистохимични маркери показват твърде голямата прилика с бъбречните карциноми, хепатоцелеарните и карциномите на супрареналните жлези. По наше мнение предварителна биопсия е неоправдана поради опасност от профузно заплашващо живота кървене. Тази опасност съществува и при иглените биопсии (Monabati, A. et all. 2002; Schipper, et all. 2004).

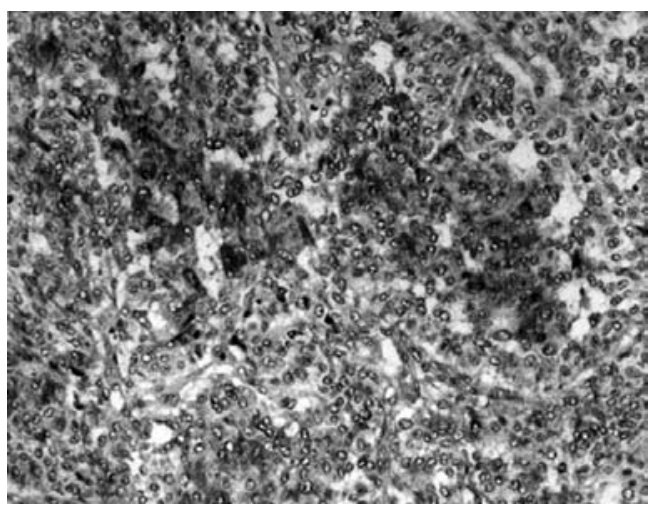

Фиг. 4. Позитивна реакция за Chromogranin в главните клетки

\section{Диференциална диагноза}

Цервикалните параганглиоми се разрастват като обемно заемащи тумори в областта на латералната страна на шията най-често в паракаротидното пространство, и то почти без оплаквания. Това налага диференциално диагностично детерминиране от шийна аденопатия от бенигнен или малигнен характер, нерядко срещаните в тази зона шийни кисти, смесени тумори на малките слюнчени жлези, неврогенни тумори, аневризма на каротиса, липоми, хемангиоми и др. 
Терапия - богатството на кръвоносни съдове и топиката на параганглиомите около магистралните съдове, независимо от високите реанимационни и хирургически възможности, днес все още се запазва високата честота на фатални постоперативни инциденти (Foote, RL. et all. - 2002) независимо от внедрената предоперативна емболизация. В момента има две техники, които са актуални и се предлагат - хирургическото отстраняване на тумора и конвенционалната лъчетерапия (Liapas, CD. et all. - 2000; Hinerman, RW et all. - 2002).

\section{Терапия на цервикалните параганглиоми}

Поради интензивната циркулация с огромното струпване на кръвоносни съдове и анатомичната локализация на параганглиомите, тяхното техническо отстраняване и днес представлява огромен риск за живота на пациентите. Различните терапевтични опции в литературата са интерпретирани твърде контроверсно. Все още като основна терапия на гломусните тумори се разполага главно с две технически възможности: хирургично отстраняване на туморната лезия и конвенционалната радиотерапия. При югулотимпаналните локализации също и възможностите на стереотактичната льчетерапия (gamma knif), а в единични строго прецизирани случаи - перманентна емболизация (Boyle, JO et all. 1990). Независимо от радикалното хирургическо елиминиране на параганглиома, съпроводено с рисковете за абондантна хеморагия, рецидивите в близко или далечното бъдеще не са изключени.

Терапия на цервикалните параганглиоми - това е единствената локализация, при която може да се обсъжда възможността за радикална хирургическа интервенция, последвана от конвенционална лъчетерапия. Туморите като правило в този регион разрастват бавно и след компетентна преценка и след емболизация може да се пристъпи към т. нар. wait and scan, т.е. изчакване и сканиране. Тук от особено значение са факторите големина и локализация на тумора, възраст на пациента и неговото здравословно състояние, предоперативното състояние на черепно-мозъчните нерви и др.

Хирургическата екстирпация - тоталното отстраняване на параганглиома в тази зона датира от преди около 130 години. Развитието днес на модерните съдови хирургически техники позволява много по-спокойно да се интервенира в тази област, но все пак в много висок морталитет от 5-30\% (Eishaikh, MA et all. 2002; Hinerman, RW. et all - 2002). Във всички случаи, когато е обхваната a. carotis interna, е задължително балонна оклузия на кръвния поток през нея за около 20 мин. Достьпьт до цервикалния параганглиом е трансцервикален с отваряне на перикаротидното пространство и оголване на a.carotis communis, оттам към bifurcatio arteriae, където се разполага туморът. Предварително се детерминират всички невроваскуларни структури, които се екартират встрани. Шансовете за продължително оперативно саниране след успешна пълноценна екстирпация на тумора се преценяват на около 89-90\% (Miller, RB. et all - 2000), но е възможна появата на редица постоянни постоперативни увреждания на нервите, напр. n. glossopharyngeum, n. vagus, $n$. hypoglossus.

Лъчетерапия - облъчването на параганглиомите не представлява куративно средство, а палиатив, който забавя силно развитието на туморния растеж и го трансформира във фиброзна тъкан. Лъчетерапията на GC и CV спира развитието на туморната лезия след лъчева доза от над $40 \mathrm{~Gy}$. Някои автори (Kim, JA et all. - 1980 ) препоръчват дозата, стагнираща развитието на тумора, да не надминава 45 -56 Gy. Като алтернатива се посочва от много автори (Boedeker, C.C. - 2011) тактиката на „wait and scan“ за пациенти с параганглиом в югулоцервикалната зона, като найподходяща за пациенти над 70 години.

Терапия на югулотимпаналните параганглиоми. В този регион са описани твърде много и различни оперативни техники, а резултатите от тях са дебатирани твърде фриволно и контроверзно. Днес като сигурен хирургически метод се представя първичното саниране на тумора посредством радикалното му отстраняване от тимпаналната кухина (Lalwani, AK. Et all. - 1993; Fisch, U. - 1982), конвенционалната или стереотактичната лъчетерапия (gamma knife). Перманентната емболизация, а така също и тактиката „wait and scan“ са доказателство, че в момента липсва единна стратегия за ефективна терапия на югулотимпаналните параганглиоми. Хирургическото отстраняване правим посредством предварително извършване на широка мастоидектомия до евентуално откриване на възможност за радикална туморна резекция. 
Много често при този оперативен модел могат да настьпят редица интраоперативни компликации, като витална хеморагия или като постоперативни парези на черепно-мозъчните нерви. При пациенти в стадии А и В, когато туморьт е локализиран в тимпаналния кавум без пропагация и инвазия към хипотимпанума, радикалното отстраняване е напълно възможно посредством ендаурален подход и създаване на широк достъп чрез радикална мастоидектомия със задна тимпанотомия. Задължително експониране на n. facialis, а при юкстакондларен достъп и перманентно невромониториране на n. facialis. При останалите стадии (по Fisch) варианти в достьпите са различни, и то предимно юкстакондиларни с висок риск от витални хеморагии и последващи тежки парези на последната група черепно-мозъчни нерви. (O'Leary MJ. et all. 1991). Според различните статистики най-висок е процентьт на дефинитивното увреждане на $\mathrm{n}$. vagus $-45,8 \%$, n. facialis $-37,9 \%$, n. hypoglossus $-36,6 \%$, n. glossopharyngeus $-31,0 \%$ и др.

Радиогенната терапия. Приема се като едно сигурно средство за туморен контрол и сравнително нисък процент на пострадиационни усложнения в сравнение с постоперативните

\section{Литература:}

1. Boedeker, CC. et all. (2004) „Laryngo-Rhino-Otol.“ 83, 585-592

2. Boedeker, CC. et all. (2009) „Skull base“ 19,17-25

3. Lee, JH. et all. (2002) „Cancer“ 94, 730-737

4. Baysal, BE. (2002) „J med. genet.“ 39, 617-622

5. Neumann, HPH et all. (2004)" JAMA“" 292, 934-951

6. D'Acri AM et all. (2002), ,Skinmed 1,94-98

7. Miller, RB. et all. (2000) „Otolarygol. Head Neck Surg.“ 122, 482487

8. Sobol, SM. et all. (1990) „Otolaryngol. Head Neck Surg.“ 102, 382-390

9. Biller, HF. et all. (1989) „Ann. Otol. Rhinol. Laryngol.“ 98, 21-26

10. Gstoettner, W. et all. (1999) „Eur. Arch. Otolaryngol.“ 256, 351355

11. Hinermann, RW. et all. (2001) „Head Neck“ 23, 363-371

12. Patetios, P. et all. (2002) „Ann. Vasc. Surg.“ 16, 331-338

13. Shick, B et all. (1998) „Laryngol. Rhinol. Otol.“ 79, 510-516

14. Stoekli, SJ. et all. (2002) „Laryngoscope“ 112, 143-146.

15. Thaber, MH. et all. (2001) „J. Laryngol. Otol. 115, 467-474

16. Shamblin,WE. et all. (1971) „Am. J. Surg.“ 122, 732-739

17. Fisch, U., D. Mattox.(1988) „Microsurgery of the Skull Base“ Thieme verlag, 149-153 такива. Както подчертахме преди, лъчевата доза е между 45 и 55 Gy, а проследената група от 31 пациенти на Chino, JP. et all. (2009) е показала пълен туморен контрол при $90 \%$ от тях. Стереотактичното облъчване (gamma knif) се прилага при пациенти с противопоказания за конвенционалното, хиперфракционирано обльчване, като определената доза се аплицира за един ден. По данни на Feigenberg, SJ. et all. (2002), провели лечението с гама нож върху група от 21 пациенти, които са били проследени 37 месеца след лечението, при нито един от тях не са открили данни за тумор или рецидиви.

Опитът ни при лечението на този тип тумори, предимно с тимпанална локализация, и тези в каротидното пространство, ни дават основание да твърдим, че при тяхното лечение е необходимо всестранно използване на всички диагностични възможности и сериозна предоперативна подготовка на пациента. Задължителна емболизация на приводящите съдове, евентуална балонна оклузия на каротиса, консулт със съдов хирург, неврохирург, хематолог и др., подсигуряване с по-голямо количество изогрупова кръв и консулт с анестезиолог с оглед изключване на други сателитни заболявания.
18. Kayani,I et all. (2008) „Cancer“ $112,2447-2455$

19. Shibahang,J.et all. (2004) „Am. J. Surg. Pathol.“ 28, 825-829

20. Au, WY. et all. (1998) „Histopathol.“ 33, 287-288

21. Kumaki, N. et all. (2002) „Endoscopic Pathol.“ 13, 149-156

22. Monabati, A. et all. (2002) „Acta cytol.“ 46, 1101-1104

23. Feigenberg, SJ. et all. (2002) „Head Neck“ 24, 384-389

24. Foote, RL. et all. (2002) „Head Neck“ 24, 332-338

25. Liapas, CD. et all. (2000) „World J Surg.“ 24, 1526-1530

26. Boyle JO. et all. (1990) „Layngoscope“ $100,896-901$

27. Elshaiki MA et all. (2002) „Int. J. Rad Oncol Biol. Phys.“ 52,953956

28. Hiermann, RW. et all. (2002) „Head Neck“ 24, 338-339

29. Kim, JA. et all. (1980) Int. J. Radiat. Oncol. Biol. Phys. 6, 815819

30. Lalwani, AK, Ak. et all. (1993) „Am. J. Otol.“ 14, 398-402

31. Fisch, U. (1982). „Ann. Otol. Rhinol. Laryngol.“ 91, 474-479

32. O’Leary, MJ et all. (1991) „Laryngoscope“ 101, 1038-1043

33. Chino, JP. et all. (2009) „Am. J. Clin. Oncol. 32, 304-307

34. Ценев, Ив. (1971) „Оториноларингология“ - София 